\title{
Uspostavljanje sustava za sigurnost pacijenata
}

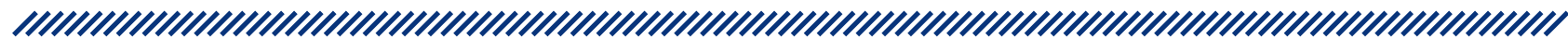

1 Maja Karić

${ }^{2,3}$ Ana Božanić

4 Andrej Starc

1 Fakultet zdravstvenih studija u Rijeci, Katedra za radiološku tehnologiju, Hrvatska

2 Klinički bolnički centar Rijeka, Zavod za medicinsku fiziku i zaštitu od zračenja, Hrvatska

3 Medicinski fakultet Sveučilišta u Rijeci, Katedra za medicinsku fiziku i biofiziku, Hrvatska

4 Zdravstvena fakulteta, Katedra za javno zdravstvo, Sveučilište u Ljubljani, Slovenija

\section{Sažetak}

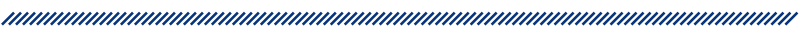

Sigurnost pacijenta vrlo je važno javnozdravstveno pitanje koje se definira kao prevencija štetnog utjecaja na pacijenta te povećavanja rizika od učestalih pogrešaka koje se događaju. Temelji se na kulturi sigurnosti koja uključuje zdravstvene radnike, zdravstvene organizacije i organizacije uključene u zdravstvo te pacijente. Sigurnost pacijenata definira se kao svaki izostanak moguće ili nepotrebne štete za pacijenta povezane sa zdravstvenom skrbi, odnosno svaka šteta koja je učinjena pacijentu, a nije uzrokovana osnovnom bolesti. Zdravstveni sustav potrebno je učiniti što je moguće sigurnijim, kako za pacijenta tako i za sve one koji pružaju zdravstvenu skrb. Sigurnost pacijenta bitna je komponenta kvalitete zdravlja, osobito u tranzicijskim zemljama, gdje na svjetskoj razini visoki udio pacijenata svake godine doživi invaliditet, ozljede ili smrt zbog nesigurne medicinske skrbi. Kultura sigurnosti pacijenta određena je kao vrijednost o tome kako procesi djeluju u organizaciji i interakciji unutar radne jedinice i organizacijskih struktura te sustava koji zajedno provode norme ponašanja koje promiču sigurnost. $U$ današnje vrijeme veliki je izazov ostvarivanje izvrsnosti u okviru zdravstvene djelatnosti, stoga je ključno postizanje, održavanje, mjerenje i unaprjeđenje kvalitete u zdravstvu. Da bi se postigla kultura sigurnosti, potrebno je razumjeti vrijednosti, uvjerenja i norme o tome što je važno u organizaciji te koji su stavovi i ponašanja povezani sa sigurnošću pacijenata očekivani i prikladni.

Ključne riječi: sigurnost pacijenata, neželjeni događaji, kultura sigurnosti

Datum primitka: 05.01.2021.

Datum prihvaćanja: 25.01.2021.

https://doi.org/10.24141/1/7/1/8

Adresa za dopisivanje:

Maja Karić

A: Viktora Cara Emina 5, 51000 Rijeka

E-pošta: maja.karic@uniri.hr

T: +385912296130 


\section{Uvod}

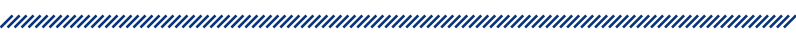

Medicinske pogreške jedan su od vodećih uzroka smrti u medicinskom području. ${ }^{1} \mathrm{U}$ cijelom svijetu se procjenjuje da jedan od 300 pacijenata doživi štetu tijekom pružanja zdravstvene zaštite, a u razvijenim se zemljama procjenjuje da je broj oštećenih pacijenata tijekom hospitalizacije jedan od deset. ${ }^{2}$ Štetu uzrokuje niz medicinskih pogrešaka ili štetnih događaja. Kada se pojave medicinske pogreške, dovode do produženog boravka u bolnicama, invalidnosti, infekcija povezanih sa zdravstvenom zaštitom, troškova parničnog postupka, izgubljenog prihoda i dodatnih zdravstvenih troškova. ${ }^{2}$ Međutim, medicinske pogreške mogu se spriječiti poboljšanjem svih aspekata sigurnosti pacijenta. ${ }^{1,2} \mathrm{Si}-$ gurnost pacijenata definira se kao „sprječavanje štete pacijenata, uključujući pogreške činjenjem ili propustom". ${ }^{3}$ Sigurnost pacijenta smatra se ključnom za održavanje kvalitete zdravstvene zaštite i postala je glavna briga zdravstvenih organizacija širom svijeta. Kultura sigurnosti koncept je koji se razvija i usredotočuje na sprječavanje medicinskih pogrešaka i održavanja sigurnosti pacijenta. Neki autori navode da je kultura sigurnosti pacijenta rezultat interakcija stavova, vrijednosti, vještina i ponašanja te obvezuje na upravljanje sigurnošću na radnom mjestu. ${ }^{4}$ Možemo govoriti o multifaktorskom okviru koji ima za cilj promicanje sustavnog pristupa prevenciji i smanjenju štete pacijentima. Za ostvarivanje kulture sigurnosti pacijenata nužno je osigurati mnoge faktore, koji uključuju učinkovitu komunikaciju, odgovarajuću statistiku, usklađenost postupaka, sigurnost okoliša, kulturu, usmjerenost vodstva, obuku te otvorenu komunikaciju o medicinskim pogreškama. ${ }^{5}$ Čimbenici kao što su slaba komunikacija, nedostatak vodstva i timskog rada, nedostatak sustava izvješćivanja, neadekvatna analiza štetnih događaja i neadekvatno znanje osoblja utječu na sigurnost pacijenata. ${ }^{6}$ Pokazalo se da postoji povezanost između elemenata sigurnosne kulture i ishoda liječenja pacijenata, sugerirajući da visoka razina sigurnosti pacijenata može poboljšati rezultate oporavka pacijenta i smanjiti troškove zdravstvene skrbi. ${ }^{7}$ Kada se govori o sigurnosti pacijenta, svaka zemlja trebala bi imati ili ima strategiju razvoja koja se sastoji od proaktivnih, preventivnih i sustavnih pristupa. U Republici Hrvatskoj izrađen je nacrt Nacionalni program za sigurnost pacijenata 2019. - 2023. u kojem se navode plan, ciljevi i djelovanja za provedbu strategije sigurnosti pacijenata. ${ }^{8}$

\section{Programi unaprjeđenja sigurnosti pacijenata}

Svjetski savez za sigurnost pacijenata 2004. godine skrenuo je pozornost na problem sigurnosti pacijenta, uspostavljanje i jačanje stručnog i znanstvenog interesa za unaprjeđenje sigurnosti pacijenata i kvalitete zdravstvene zaštite, uključujući medikamentoznu primjenu, medicinsku opremu te informatičku tehnologiju. ${ }^{9}$

Programi su koji se odnose na sustavne aspekte za unaprjeđenje sigurnosti pacijenta: program za podizanje svijesti o utjecaju bolničkih infekcija te njihovo suzbijanje (engl. Clean Care is Safe Care - čista skrb je sigurna skrb), razvoj međunarodne klasifikacije u svrhu pojašnjenja koncepta i definicije sigurnosti pacijenta (engl. International Classification for Patient Safety - taksonomija za sigurnost pacijenta), unaprjeđenje sigurnosti kirurških pacijenata (engl. Safer Surgery Saves Lives - sigurnije operacije čuvaju živote), poticanje razvoja istraživačkih projekata (engl. Research to Improve Patient Safety - istraživanje za unaprjeđenje sigurnosti pacijenata), sustavno izvješćivanje i učenje o neželjenim događajima (engl. Reporting and Learning - izvješćivanje i učenje). ${ }^{8}$

Svjetska zdravstvena organizacija kontinuirano provodi i promiče strategije o sigurnosti pacijenta i pridonosi važnosti istraživanja za bolje razumijevanje uzroka neželjenih događaja i razvoju programa sigurnosti pacijenata i kulture sigurnosti. Preporuka je donesena 2009. godine i odnosi se na uspostavljanje nacionalnih programa za sigurnost pacijenta, informiranje pacijenata i njihovo uključivanje u proces razvoja, poticanje kulture sigurnosti i učenje na pogreškama posebice poticanje sigurnosti kroz izobrazbu i usavršavanje zdravstvenih radnika, razvoj klasifikacija i mjerenja, razmjenu znanja, iskustava i primjenu najbolje prakse na području sigurnosti pacijenata. ${ }^{10}$

\section{Ciljevi i procjena sigurnosti pacijenata}

Opći je cilj u Nacionalnom programu jačanje kapaciteta sudionika u zdravstvu u cilju unaprjeđenja kulture sigurnosti pacijenata, dok su specifični ciljevi podizanje svjesnosti o sigurnosti pacijenata, razvoj i unaprjeđenje sustava praćenja, mjerenje i izvješćivanje, smanjenje rizika za neželjene događaje, razvoj istraživanja na području sigurnosti pacijenata. ${ }^{8}$

Prva je faza u razvoju kulture sigurnosti pacijenata u nekom zdravstvenom sustavu procjena trenutačnog stanja, uz uvažavanje svih prednosti, ali i nedostataka 
postojeće organizacije sustava. Pravilnik o standardima kvalitete zdravstvene zaštite i načinu njegove primjene utvrđuje ukupno devet skupina standarda kvalitete zdravstvene zaštite i način njihove primjene. Naime, definirani su standardi koji sadrže zahtjeve za prepoznavanje i otkrivanje neželjenih događaja, medicinske pogreške, zahtjev za uspostavljanje dokumentiranog sustava sigurnosti pacijenata, praćenje neočekivanih neželjenih događaja i ostalih neželjenih događaja. ${ }^{10,11}$

Ključni problemi prilikom procjene:

- prikupljanje informacija - postojeći bolnički informacijski sustavi ne podržavaju prikupljanje informacija o pokazateljima u skladu s međunarodnim standardima, što predstavlja administrativno opterećenje u prikazu stvarnog stanja

- nedostatno izvješćivanje o slučajevima, posebice pokazatelja kao što je poslijekirurška infekcija rane, poslijekirurška plućna embolija ili duboka venska tromboza, poslijekirurško krvarenje ili hematom, poslijekirurški prijelom kuka, nuspojave lijekova, dekubitalni ulkus, pad pacijenta

- nedostatno izvješćivanje o neočekivanim neželjenim događajima

- nedostatna primjena sigurnosnih praksi, standardiziranih protokola i odgovarajućih alata

- praćenje sigurnosti pacijenata putem definiranih pokazatelja u okviru vrijedećih propisa (bolničke zdravstvene ustanove)

- kultura sigurnosti nije zadovoljavajuće razine

- djelomično uspostavljene aktivnosti povezane sa sprječavanjem i kontrolom infekcija povezanih sa zdravstvenom skrbi

- edukacija nije obvezna u svim domenama učenja zdravstvenih radnika

- nedovoljno razvijena svijest o sigurnosti pacijenta kod samih pacijenata i kod udruga pacijenata, potrebna je edukacija nedostatni resursi za uspostavljanje nacionalnog praćenja i unaprjeđenja sigurnosti pacijenta na svim razinama. ${ }^{8}$

\section{Prijava i analiza neželjenih događaja}

Sustavno izvješćivanje o neželjenim događajima daje jasnu sliku kada moramo učiti na pogreškama. Podržavanje okruženja koje potiče prijavljivanje neželjenih događaja mora biti bez kazni i optuživanja zdravstvenih radnika. Dakako da je potrebno razlikovati takve slučajeve od nebrige i nemara koji ulaze u disciplinsku dimenziju. Razvojem sustava prijavljivanja i učenja o neželje- nim događajima potrebno je obuhvatiti sve djelatnike koji pružaju zdravstvenu uslugu. Dobra informatička i komunikacijska struktura omogućuje bolji pristup prijavi za što veći broj podataka u procesu izvješćivanja i koordinacije same aktivnosti. ${ }^{8}$ Studije provedene u bolnicama Irana prikazuju da najveću učestalost među medicinskim pogreškama imaju sistemske pogreške, administrativne pogreške i štetni lijekovi te se smatra da jedan od 100 do 150 pacijenata umire od navedenih medicinskih pogrešaka. ${ }^{12}$ Prijavljeni su brojni slučajevi medicinske pogreške, što je vodeći uzrok obolijevanja i smrtnosti u svijetu. Problem je u izvještavanju, a ono je vrlo važno za smanjenje broja pogrešaka. Stoga prijavljivanje medicinske pogreške znatno utječe na dobrobit pacijenata. ${ }^{13}$ Izgradnja sigurne kulture za prijavljivanje medicinske pogreške zahtijeva okruženje bez okrivljavanja, straha i kazne. Iz straha od kazne i posljedica koje bi mogla odrediti bolnička uprava, zdravstveni djelatnici rjeđe prijavljuju pogreške. ${ }^{14}$

\section{Mjere sigurnosti i edukacija zdravstvenih djelatnika o sigurnosti pacijenata}

U skladu s međunarodnim standardima, prati se i mjeri sigurnost pacijenata praćenjem pokazatelja sigurnosti. Usporedbom nacionalnih i međunarodnih pokazatelja identificiraju se problemi koji ugrožavaju sigurnost pacijenata. Važno je uspostaviti standardizirane obrasce koje je potrebno popuniti relevantnim podacima. Obrasci moraju biti jednostavni i dostupni, što omogućuje adekvatna informatička potpora i elektronički registri koji pohranjuju podatke. Prikupljeni se podaci obrađuju te upotrebljavaju za unaprjeđenje sustava. ${ }^{8}$ Studija koja je provedena 2019. u međunarodnoj bolnici Royal Care odnosila se na adekvatnost propisivanja liječničkih recepata te se ustanovilo da je kod većine recepata nedostajalo važnih informacija o pacijentu ili lijeku, što je upućivalo na povećan rizik od pogreške u upotrebi lijeka. Upotreba strukturiranog obrasca za naručivanje lijekova može poboljšati i spriječiti neadekvatnu ili pogrešnu upotrebu lijekova. ${ }^{15}$ Također je nužan razvoj infrastrukture i što dostupnijeg informatičkog programa za prepoznavanje, primjenu, analizu izvještavanje o medicinskim greškama, npr. MERIS. ${ }^{16}$

Sigurnost pacijenata izostavljena je iz obrazovnih programa zdravstvenih radnika te ju je potrebno uvesti u obrazovanje te provoditi i cjeloživotno učenje da bi se razvile potrebne kompetencije za pružanje sigurne zdravstvene skrbi. Osiguranjem edukacije, odnosno učenjem o sigurnosti pacijenata na svim razinama obrazovanja zdravstvenih djelatnika, daje se jasna poruka 
da je upravo pacijent u fokusu zdravstvenog sustava. Osim zdravstvenih radnika, potrebno je aktivno sudjelovanje pacijenata i građana u procesu sigurnosti pacijenata. Ključnu ulogu imaju udruge pacijenata te mediji kako bi se promijenila percepcija odgovornosti za sigurnost pacijenata. ${ }^{8}$ Studija provedena u Egiptu na primjeru medicinskih sestara kod prijave medicinske pogreške dokazala je da su medicinske sestre koje rade u nastavnim bolnicama postigle veći ukupni rezultat mjera sigurnosti pacijenata nego medicinske sestre koje ne rade u nastavnim bolnicama i nisu dovoljno educirane. ${ }^{17}$ Druga istraživanja navode slične rezultate, koji pokazuju da medicinske sestre u velikim bolničkim sustavima poznaju sigurnost pacijenata jer posjeduju visoku organizacijsku kulturu učenja. ${ }^{18}$

\section{Procesi i kultura sigurnosti pacijenata}

Jačanju sustava i procesa sigurnosti pacijenata znatno pridonosi klinička praksa temeljena na dokazima i znanstvenim spoznajama sa standardiziranim alatima i metodama. Primjenu sigurnosnih kliničkih praksi navodi Svjetska zdravstvena organizacija, a odnosi se na kiruršku kontrolnu listu, higijenu ruku, usklađivanje primjene lijekova te sustav ranog upozorenja u pedijatriji. Sigurnosne prakse imaju za cilj poboljšati sustav sigurnosti pacijenata na nacionalnoj i regionalnoj razini u okvirima zdravstvenog sustava. ${ }^{8} \mathrm{U}$ studiji u brazilskoj javnozdravstvenoj ustanovi na intenzivnoj njezi koja je provedena 2009. i 2010. ustanovljen je deficit znanja zdravstvenih radnika o jatrogenim bolestima te načinu njihova sprječavanja, a istaknuto je i slabo pridržavanje tehnike higijene ruku. Suprotno tome, istaknuti su pozitivni pokazatelji u sestrinskoj intenzivnoj njezi u pogledu sigurnosti pacijenata u odnosu na upotrebu protokola skrbi, poput sprječavanja padova pacijenata. Vrijedi naglasiti da su istraživanja o sigurnosti pacijenata u Brazilu u porastu, pa i ova studija predlaže razmišljanje o boljoj edukaciji zdravstvenog osoblja o skrbi te primjeni alata za poboljšanje sigurnosti pacijenata. ${ }^{19}$

Kultura sigurnosti pacijenata zahtijeva novi način razmišljanja i djelovanja, predanost promatranju sigurnosti kao prioriteta na svim razinama organizacije i jačanje partnerskog odnosa s pacijentom. Kada se govori o razvoju kulture sigurnosti, važno je naglasiti da je nužno jako vodstvo, planiranje i nadzor. ${ }^{20}$ Također je neizmjerno važna suradnja svih sudionika u sustavu zdravstvene zaštite, od zakonodavne vlasti do kliničkih timova. Razina kulture sigurnosti može se mjeriti jer omogućuje uvid u trenutačno stanje, kao i procjenu potrebnog unaprjeđenja sigurnosti. Razvijeni su upitnici o kulturi sigurnosti koji se najčešće koriste. ${ }^{8} \mathrm{U}$ najširoj su upotrebi u Sjedinjenim Američkim Državama dva upitnika za procjenu sigurnosti pacijenata, a primjenjuju ih i druge zemlje, modificirane prema potrebama zdravstvenih organizacija. Prvi je Upitnik o stavovima sigurnosti (engl. The Safety Attitudes Questionnaire - SAQ) Sveučilišta u Teksasu iz 2003.21 Drugi poznati upitnik razvijen je u okviru Agencije za kvalitetu i istraživanje u zdravstvu (Agency for Healthcare Research and Quality - AHRQ) 2003./2004. pod nazivom Upitnik o kulturi sigurnosti pacijenta u bolnici (engl. Hospital Survey on Patient Safety Culture - HSPSC). ${ }^{22}$

Upitnik mjeri nekoliko kategorija kulture sigurnosti na razini zdravstvene ustanove ili odjela:

- očekivanja rukovoditelja i njihove aktivnosti na promicanju sigurnosti

- edukacija, rad na poboljšanju

- timski rad na poslovima

- otvorenost u komunikaciji

- prijava pogrešaka i analiza

- nekažnjavanje pogrešaka

- popunjenost ljudskih resursa

- utjecaj i podrška vodećih struktura o sigurnosti pacijenata

- timska komunikacija između bolničkih odjela

- način primopredaje i otpust pacijenata

- učestalost izvještavanja o neželjenom događaju

- stupanj bolesnikove sigurnosti na odjelu

- broj podnesenih izvještaja o neželjenom događaju.

$\mathrm{Na}$ temelju analize podataka prikupljenih upitnikom unaprjeđuje se sustav.

\section{Zaključak}

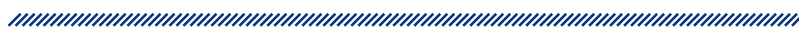

Potreba za sigurnošću jedna je od osnovnih ljudskih potreba. Stoga je potrebno izgraditi sustav koji će osigurati suvremenu i sigurnu zdravstvenu skrb te provođenje medicinske dijagnostike i liječenja u skladu s postavljenim standardima. Kontinuirano prikupljanje i analiza dobivenih podataka o neželjenim događajima, učenje na pogreškama i uspostavljanje standarda nužni su kako bi se mogla mjeriti sigurnost i kvaliteta zdravstvene usluge. 
Pružanje zdravstvene skrbi koja se provodi na temelju vrhunskih znanstvenih spoznaja s kliničkim iskustvom usmjerava sustav na kritičku procjenu istraživačkih podataka, kliničkih smjernica te drugih izvora informacija. Svrha postavljanja dobre dijagnoze rada sustava omogućuje ispravnu detekciju i analizu problema u cilju da se adekvatno poduzmu mjere za njegovo suzbijanje i prevenciju. Nažalost, trend prijavljivanja neželjenih događaja ili pogrešaka u zdravstvenim organizacijama i ustanovama pridruženim zdravstvu prilično je slab. Stoga je potrebno poduzeti potrebne korake kako bi se sudjelovanje u programu sigurnosti pacijenata uistinu provodilo. Poboljšanje i razvoj kvalitete zdravstvene zaštite, posebice sigurnosti pacijenta, zahtijeva znanje, edukaciju, izbor i primjenu metoda i alata prilagođenih mogućnostima i specifičnostima pojedinih zdravstvenih organizacija. Dakako, nužno je konstantno provoditi studije o kulturi sigurnosti pacijenata na svim razinama zdravstvenih ustanova te težiti poboljšanju sigurnosti u zdravstvenoj skrbi.

\section{Reference}

1. Kohn LT, Corrigan JM, Donaldson MS. To Err is Human: Building a Safer Health System. Institute of Medicine, Washington, DC. 2000.

2. World Health Organization. Patient Safety. 2019. Dostupno na: https://www.who.int/features/factfiles/patient_safety/ patient-safety-fact-file.pdf?ua=1 (pristupljeno 11.2.2020.).

3. Institute of Medicine: Keeping Patients Safe: Transforming the Work Environment of Nurses. National Academies Press, Washington, DC. 2004. Dostupno na: https://www.ncbi. nlm.nih.gov/books/NBK216190/ (pristupljeno 8.2.2020.).

4. Nieva VF, Sorra J. Safety culture assessment: a tool for improving patient safety in healthcare organizations. Quality and Safety in Health Care, 2003; 12 (2), 17-23.

5. Joint Commission Resources: Front line of Defense: The Role of Nurses in Preventing Sentinel Events, $2^{\text {nd }}$ ed. Joint Commission Resources, Oakbrook Terrace, IL. 2007. Dostupno na: https://aacnjournals.org/ccnonline/article-abstract/27/6/75/1046/Front-Line-of-Defense-The-Role-ofNurses-in?redirectedFrom=fulltext (pristupljeno 9.2.2020.).

6. Department of Health and Children: Building a Culture of Patient Safety - Report of the Commission on Patient Safety and Quality Assurance. Dublin. 2008. Dostupno na: https:// www.lenus.ie/handle/10147/65918 (pristupljeno 8.2.2020.).

7. Clarke, S. \& Ward, K.: The role of leader influence tactics and safety climate in engaging employees' safety participation. Risk Analysis. 2006; 26 (5), 1175-1185.
8. Republika Hrvatska, Ministarstvo zdravlja: Nacrt - Nacionalni program za sigurnost pacijenata 2019. - 2023. Dostupno na: https://zdravlje.gov.hr/pristup-informacijama/ savjetovanje-sa-zainteresiranom-javnoscu-1475/otvorena-savjetovanja/nacrt-prijedloga-nacionalnog-programa-za-sigurnost-pacijenata-2019-2023/3576 (11.2.2020.).

9. Omidia L, Reihane A, Esmaeil H, Esmaeil Z. An intelligent algorithm for assessing patient safety culture and adverse events voluntary reporting using PCA and ANFIS, International Journal of Risk \& Safety in Medicine, 2018/2019, 30, 45-58.

10. Pravilnik o akreditacijskim standardima za bolničke zdravstvene ustanove, Narodne novine, broj 31/11.

11. Pravilnik o standardima kvalitete zdravstvene zaštite i načinu njihove primjene, Narodne novine, broj 79/11.

12. Khammarnia M, Setoodehzadeh F. Medical Error as a Challenge in Iran's: Health System. Health Scope, 2017, 6, 1-11.

13. Nida A, Haya UM, Naveena F, Abdul L, Tahir SS. Medical Errors in a Newly Established Teaching Hospital - Some Lessons Learnt for Better Practices, National Journal of Health Sciences. 2019; 4, 136-140.

14. National Health Service: Learning from patient safety incidents. 2017. Dostupno na: https://improvement.nhs. uk/resources/learning-from-patient-safety-incidents/

15. https://youtu.be/ALXROv7ryck (pristupljeno 11.2.2020.).

16. Abdalrahman IB, Elwidaa SHA, Elgenaid SN, Suliman ET, Osman AM, Abbas NMA, Banani YA, Mohamed T, Mohamed AAMA, Mustafa HO, Alkurdi TOHA, Elias M, Zeinelabdin MA. Medication Safety, Assessment of Adequacy of Prescription in Royal Care International Hospital, IOSR Journal of Dental and Medical Sciences. 2019; 18 (10) 8, 66-71.

17. Vozikis A. Information management of medical errors in Greece: The MERIS proposal: International Journal of Information Management. 2009; 29, 15-26.

18. Ammouri AA, Tailakh AK, Muliira JK, Geethakrishnan RA, Kindi SN. Patient safety culture among nurses: International Nursing Review, International Council of Nurses, 2014.

19. Hatam N, Keshtkar V, Forouzan F, Peivand B. Patient safety culture status in teaching hospitals: a case of Shiraz University of Medical Sciences. Middle East Journal of Scientific Research, 2012, 12 (7), 970-975.

20. Ramos EM, Lima MD, Aragão V, Baez Sarti ECF. latrogenic Related to the Knowledge Deficit of Patient Safety in the Care: A Descriptive Analysis; International Journal of Critical Care and Emergency Medicine, 2019, 5, 3.

21. Musa K, Abduljewad H, Abate L, Shemsu N, Geroma M. Patient Safety Culture and Associated Factors Among Health Care Providers in Bale Zone Hospitals, Southeast Ethiopia: An Institutional Based Cross-Sectional Study, Drug, Healthcare and Patient Safety (2020) 12, 1-14.

22. University of Texas, Safety Attitudes Questionnaire. Dostupno na: https://med.uth.edu/chqs/survey/ (pristupljeno 11.2.2020.).

23. Agency for Healthcare Research and Quality. Hospital survey on Patient Safety Culture. Dostupno na: https:// psnet.ahrq.gov/issue/updates-hospital-survey-patientsafety-culture - 2k - 2019-11-29 


\section{ESTABLISHING A SYSTEM FOR PATIENT SAFETY}

1 Maja Karić

2,3 Ana Božanić

4 Andrej Starc

1 Fakultet zdravstvenih studija u Rijeci, Katedra za radiološku tehnologiju, Rijeka, Hrvatska

2 Klinički bolnički centar Rijeka, Zavod za medicinsku fiziku i zaštitu od zračenja, Rijeka, Hrvatska

3 Medicinski fakultet Sveučilišta u Rijeci, Katedra za medicinsku fiziku i biofiziku, Rijeka, Hrvatska

4 Zdravstvena fakulteta, Katedra za javno zdravstvo, Sveučilište u Ljubljani, Ljubljana, Slovenija each year due to unsafe medical care. Patient safety culture is defined as a value which describes how processes work in organization and interaction within the work unit and organizational structures and systems that together implement behavioral norms that promote safety. Nowadays, there is a great challenge to achieve excellence within the healthcare industry, so lately it has been crucial to achieve, maintain, measure and improve quality in health care. To achieve a culture of patient safety it is necessary to understand the values, beliefs and norms about what is important in the organization and which attitudes and behaviors related to patient safety are expected and appropriate.

\section{Abstract}

Patient safety is a very important public health issue that is defined as preventing adverse effects on the patient and increase in risk of frequent errors that occur. It is based on a patient safety culture that includes healthcare professionals, healthcare organizations and organizations involved in healthcare, and patients. Patient safety is defined as any absence of possible or unnecessary damage to the patient related to health care, or any damage done to the patient that is not caused by the underlying disease. The healthcare system needs to be made as safe as possible, both for the patient and for all those who provide health care. Patient safety is an essential component of health quality, especially in transition countries, where a high proportion of patients worldwide experience disability, injury or death 